\title{
An Integrated Approach for Selecting Information Systems: A Case Study
}

\author{
Konstantinos Viglas ${ }^{1}$, Panos Fitsilis ${ }^{2}$, Achilles Kameas ${ }^{1}$ \\ ${ }^{1}$ Hellenic Open University, Patras, Greece \\ ${ }^{2}$ Technological Educational Institute of Larissa, Larissa, Greece \\ E-mail: kviglas@yahoo.com; fitsilis@teilar.gr; kameas@eap.gr \\ Received March 22, 2011; revised April 28, 2011; accepted May 4, 2011
}

\begin{abstract}
There is agreement within the academia and practitioners that IT investments should be evaluated in order to be in agreement with the overall strategic objectives of an organization. Moving toward to this direction, the aim of this paper is to present a model that combines Balanced ScoreCard (BSC) methodology and a decision support method such as Analytic Network Process (ANP) for assisting the selection of an IT system. The proposed model provides a simple, flexible and easy to use approach that can be applied by organizations to support their investment decisions. The proposed approach is presented through a case study for selecting a Quality Management Information System for a large Greek retailer.
\end{abstract}

Keywords: Multi-Criteria Decision making, Balanced Scorecard, Analytic Network Process

\section{Introduction}

Information system selection plays an important role in all modern organizations since their smooth and efficient operation depends heavily on Information Systems (IS). Furthermore, large software systems are built by using components developed by others (commercial or open source), therefore an increasing need appears to select the right system, the appropriate components in a systematic, factual, objective, and cost efficient manner.

The selection process is far from being trivial since it has to combine many, complex and in many cases contradicting factors such as: business strategy, numerous functional and non-functional requirements, operating priorities, availability of resources etc. [1,2].

Traditional approaches and methods for selecting information systems focus on well-known financial measures, such as the Return On Investment (ROI) [3], Net Present Value (NPV), the Internal Rate of Return (IRR), Cost/ Benefit Analysis (CBA) and the payback period [4,5]. However, these methods cannot offer the analytical power needed for today's complex decisions, since they fail in quantifying intangible criteria.

Multi-criteria decision making (MCDM) can be quite useful to support an IT system selection process. Although there is no generic methodology that can be adopted for selecting a software package of any type, literature reviews on evaluating software products suggest that users and decision makers can receive a lot of support, if they decide to adopt an MCDM method [6]. In particular, the findings of review studies [6,7] present that the Analytic Hierarchy Process (AHP) has been widely and successfully used in evaluating several types of software packages (e.g., MRP/ERP systems, simulation software, CAD/CASE systems, Knowledge Management systems etc.). The AHP method was introduced by Saaty [8] and its primary objective is to classify a number of alternatives (e.g., a set of candidate software packages) by considering a given set of qualitative and/or quantitative criteria, according to pair wise comparisons/judgments provided by the decision makers. AHP results in a hierarchical leveling of the selection criteria, where the upper hierarchy level is the goal of the decision process, the next level defines the selection criteria which can be further subdivided into subcriteria at lower hierarchy levels and, finally, the bottom level presents the alternative decisions to be evaluated.

A newer version of AHP is Analytic Network Process (ANP) and is considered as a generic form of AHP. The main difference between AHP and ANP is that AHP structures a decision problem into levels forming a hierarchy, while the ANP is using a network approach. ANP allows both interaction and feedback within clusters of elements (inner dependence) and between clusters (outer dependence). Such feedback captures the complex effects of inter- 
play in complex situations in a better way, especially when risk and uncertainty are involved [9,10].

Nevertheless, the overall decision process should be filtered in the context of business strategy. This can be accomplished with the application of Balanced Scorecard Method (BSC). Not only being a methodology, BSC is considered a performance measurement framework that provides an integrated look at the business performance of an organization by a set of both financial and non-financial objectives.

Obviously, the selection of the appropriate information system can offer strategically, tactical and operational advantages to an organization. However, this selection is a complex process that should be in line with the overall strategy, take into account financial aspects and at the same time be analytical.

In our paper, through the case study under investigation, we present a model that starts at the high level with the strategic objectives of an organization, as they have been described by the use of BSC, and ends with the application of ANP method, which quantifies and balances the low level criteria.

The application of this model can greatly assist both the high and mid level management in approaching the decision process from a different perspective, while at the same time this decision is factual, consistent and well documented.

The structure of the paper is as follows, Section 2 presents the relevant literature background and an overview of the employed methodologies. Section 3 presented the proposed approach. In Section 4 we demonstrate the proposed approach though the presentation of a case study. The case study is focusing on the selection of a Quality Management System (QMS) for a multinational food retail organization. Conclusions and extensions of the research work are addressed in chapter 5 .

\section{Background}

\subsection{Financial Methodologies for IS Selection}

Traditionally, investment appraisal was based on financial accounting methodologies, such as return on investment and payback period. Their application has been criticized as biased [11], since they tend to overlook market status, human capital and process improvement, growth opportunities etc. As such, they cannot measure objectively past performance and forecast future outcomes. However, financial indices are always considered important since they measure the monetary value of the IT investment.

Net Present Value (NPV) is defined as the total Present Value (PV) of a time series of cash flows. It is a standard method for using the time value of money to appraise long-term projects [12]. It is defined with the formula

$$
N P V=C_{0}+\sum_{1}^{t} \frac{C_{t}}{(1+r)^{t}}
$$

where $C_{0}$ defines the initial investment, $C_{t}$ is the valuation of the current cash flow and $r$ is the discount rate. Intuitively, $N P V$ defines what would cost today a cash flow that will take place in the future. In practical terms, if $N P V$ is positive then the investment adds value to the business, the project is profitable and therefore the IT system should be developed or purchased.

Similar to NPV's measure is IRR (Internal Rate of Return), which is defined with the formula

$$
C_{0}+\sum_{1}^{t} \frac{C_{t}}{(1+I R R)^{t}}=0
$$

Semantically, IRR is the calculation of the rate that nullifies NPV [13]. In case of selection between mutually exclusive alternatives and especially when the initial cost is different, incremental analysis shall be applied in order to evaluate the IRR of the difference between two alternatives with the smaller cost [14]. The reason behind the application of incremental analysis lies to the fact that $I R R$ is measuring one single alternative.

Return of Investment ( $R O I)$, is a popular accounting method for evaluating investments. ROI defines how much an organization gets from the spent amount of money. Therefore, ROI helps an organization to decide on different investment alternatives. $R O I$ is defined as

$$
R O I=\frac{\text { investment profit }}{\text { investment } \cos t}
$$

and provides a comparison of the investment result versus the investment cost [13]. Investment profit is defined as the expected income minus the investment cost, where the investment cost is the initial cost plus the cost during the life-cycle of the project.

Finally, Payback Period (PP) is used to evaluate investments where the payback period of the investment (the period needed to replenish the initial cost) is compared to a predefined time period, the so-called cut-off period. It is calculated by deducting the initial cost of an investment from the financial benefits of the investment throughout the defined periods (months, years, etc.). E.g. if the payback period is three years and the result of the above mentioned operation on the third year (or earlier) is bigger than zero, the investment must take place, otherwise it must not.

\subsection{Multi-Criteria Decision Making with Analytical Processes}

An MCDM method (like AHP and ANP) overcomes the 
limitations of the conventional financial methods as it combines a set of criteria in order to reach to a decision, handles both quantitative and qualitative criteria and is applicable to both individual and group-based decision making.

These advantages have caused the wide application of AHP to multi-criteria decision making problems, in many different sectors, including software project management and IT system procurement. Two representative examples of software engineering project management problems that gained a lot of attention to be supported by AHP are: 1) prioritizing software requirements and 2) selecting Component off the Self systems (COTS). In both problems AHP has been used to compare software requirements [15] or COTS products $[16,17]$ by taking into account the relative importance between value and cost of each requirement/COTS product, respectively.

AHP is based on three basic concepts (see Figure 1):

- Complexity Analysis: A hierarchical tree is created with criteria, sub-criteria and alternative solutions as the leaves.

- Calculation/Estimation is executed in every tree level based on a 1 to 9 scale in order to measure priorities. More specifically, a pair wise comparison takes place in every tree level with regards to the parent node. The goal node in the hierarchical tree exists only to highlight the top-down analysis of the methodology.

Synthesis with ultimate goal to extract the final priorities of the alternatives.

There are two difficult points related with the practical application of AHP. Firstly, when determining “crisp” comparative values, any uncertainties on judgments of decision makers cannot be easily handled and, secondly, when there are dependencies among the selection criteria. In such a case, the Analytic Network Process (ANP) can be used, an AHP extension that handles both intra- and inter-dependencies among clusters of selection criteria [9,18].

ANP is rather a special case (or an extension) of AHP [9] and is based on the same principles as AHP. Its ba-

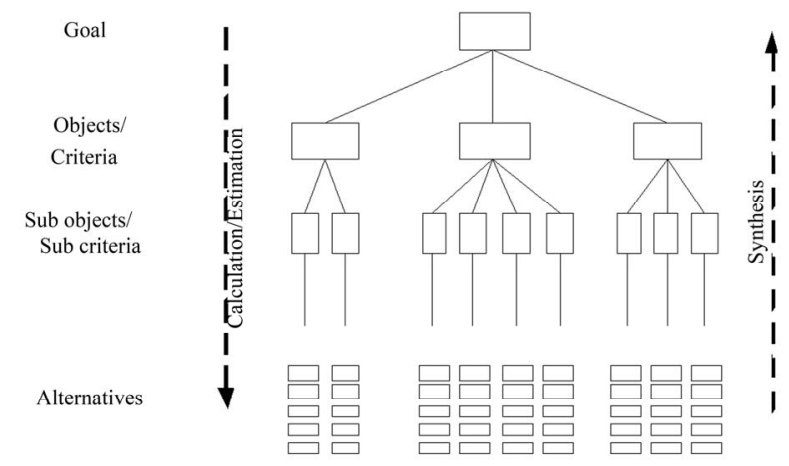

Figure 1. AHP hierarchical tree. sic difference is that a network is created instead of a hierarchy (see Figure 2), where there is no specific Goal object but instead the sub-criteria of AHP stand as the elements of the objects (clusters in ANP terminology). Still, the main difference is the feedback, where the evaluation of criteria with regard to alternatives is allowed, against the top-down approach of AHP where the importance of the alternatives is examined with regards to criteria. The goal of selecting the best alternative is utterly produced by the evaluation of the objects/clusters versus the alternatives and vice versa.

\subsection{Performance Measurement with Balanced Scorecard}

Balanced ScoreCard (BSC) [19] is a methodology that has achieved wide publicity among both scientists and managers. BSC is being widely accepted since it fills the gap between the development of a strategy and its realization by supporting and linking critical management processes [20]. More specifically, it takes conventional financial measures like ROI and payback period and complements them with additional ones that reflect customer satisfaction, internal business processes, and the ability to learn and grow.

The above idea is modeled with four discrete perspectives, which are used to split the overall business strategy to 1) Financial, 2) Customer, 3) Internal Business Process, and 4) Learning \& Growth dimensions (see Figure 3).

1) The Learning \& Growth Perspective provides the drivers for achieving the objectives of the other three areas of the scorecard. The key factors that constitute this perspective are: employ capabilities, information system capabilities and employee motivation, empowerment etc.

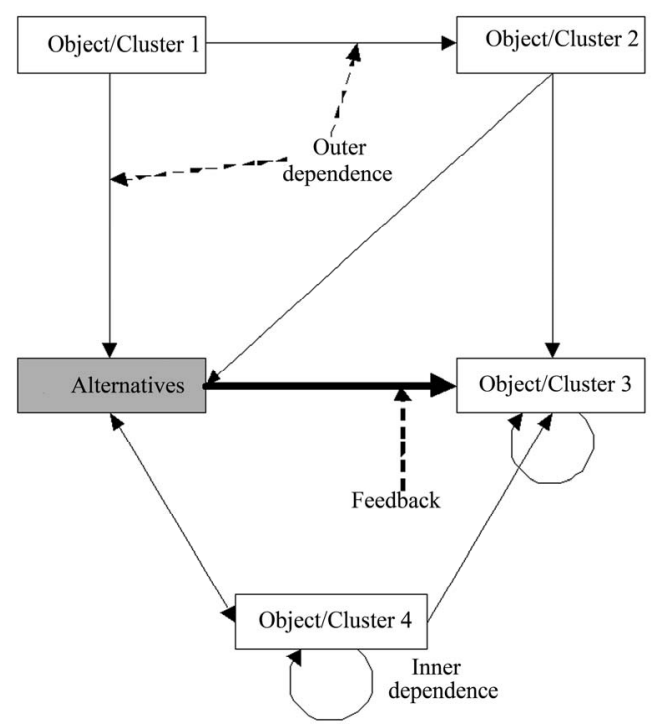

Figure 2. Connections in a network. 


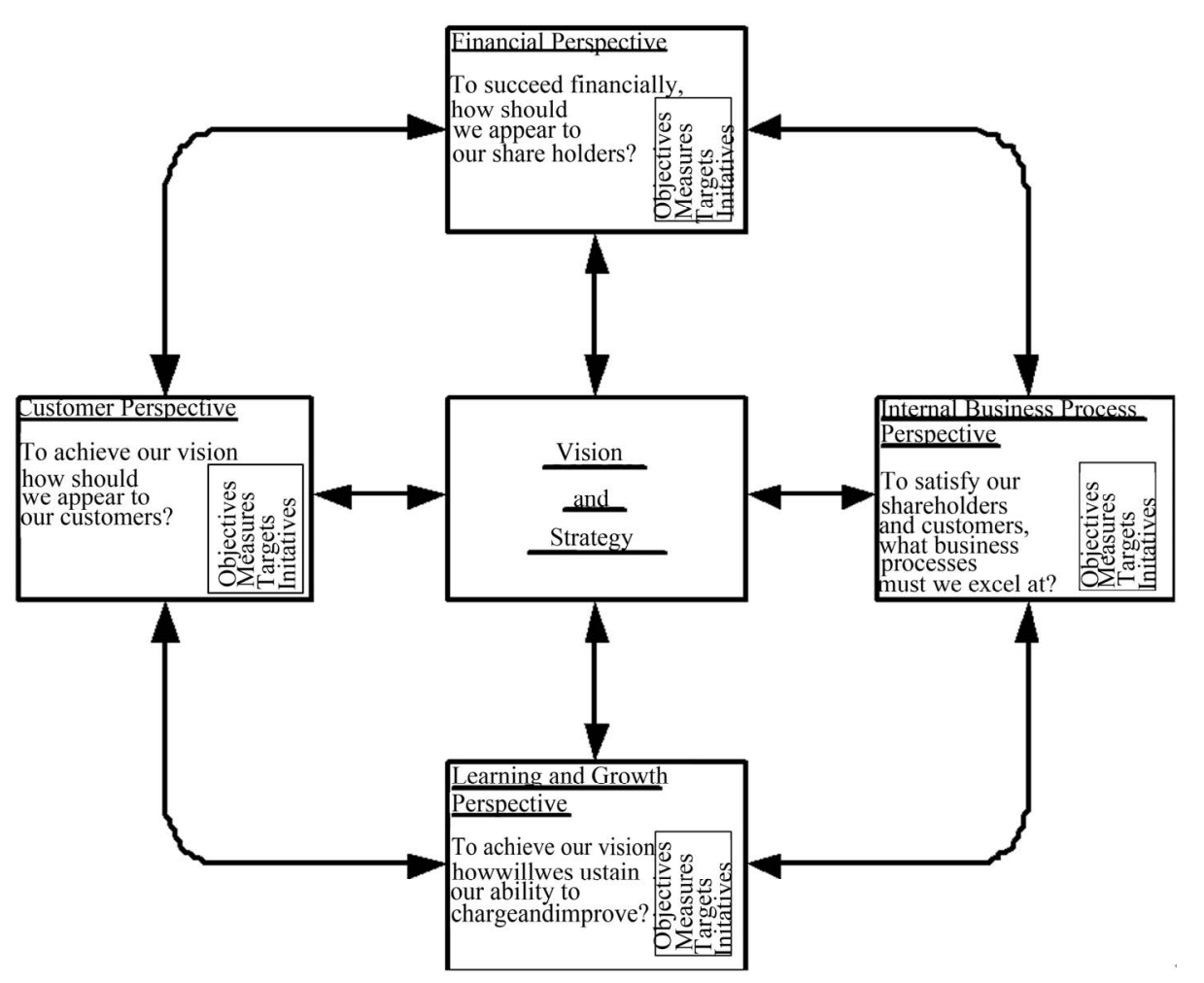

Figure 3. Synopsis of BSC perspectives (Adapted from the Balanced Scorecard by Kaplan \& Norton).

2) The Business Process Perspective refers to internal business processes. Metrics (or measures) based on this perspective allow the managers to know how well their business is running, and whether its products and services conform to customer requirements (the mission).

3) The Customer Perspective contains indices that measure customer satisfaction, via analyzing customers in groups, and via assigning business processes to products and services delivered to these groups.

4) The Financial perspective contains the typical financial performance measures, which are mainly related to profitability. The measurement criteria are usually profit, cash flow, ROI, return on invested capital (ROIC), and economic value added (EVA).

The BSC is usually complemented by a strategy map. A strategy map is a diagram that connects organization's strategic objectives in explicit cause-and-effect relationship and describes the way that value is created within the organization.

\section{The Proposed Approach}

The proposed approach is tackling the problem of strategy diffusion at different levels within the organization by offering different mechanisms at each strategic level in an integrated fashion.

Figure 4 is illustrating this approach, where BSC is used for strategy development, while for the implementation of strategic choices traditional decision support methodologies are employed.

Even though, this as an idea rather simple, literature does not offer large number of examples on how you can transform the BSC objectives and measures identified, to criteria used in a decision management methodologies for taking strategic decisions.

In the approach used, the first step is the development of BSC which is fundamental for crafting the strategy of the organization. This is considered as complex task since a strategist has to consider a large number of heterogeneous aspects, but on the other hand this is a well documented process.

The implementation of the identified strategic objectives, especially in the case of "learning and growth" perspective, involves selection of IT systems, able to meet the performance measures identified. In most cases, this selection process is done in isolation by the IT department of the organization and using criteria mostly referring to the functionality of the system.

In our approach, the selection process is strategic process which is composed of 1) an analytical selection process and 2) a financial-investment evaluation process. The analytical selection process is based on the assumption that the performance measures of the scorecard should be transformed to selection process criteria, in order to achi- 


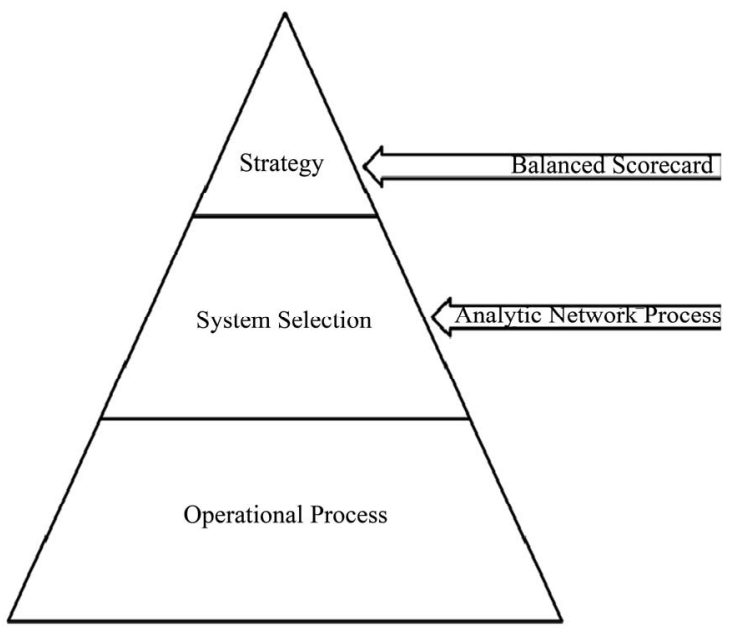

Figure 4. Pyramid of decision making levels within the organization.

eve maximum strategic alignment. At the same time, the BSC financial performance measures are used in a typical investment evaluation. The end results of these two parallel processes are combined in a qualitative way in order to conclude with the selection of the IT system and the final decision.

\section{Case Study}

This case study concerns a multinational retail organization, operating in three continents with more than 3000 Points of Sale (POS).

The problem the organization faces is the integration of its strategic plan to a framework that will optimize its performance measurement and, as a consequence, will propose measures (alternatives) to be taken to improve it in terms of Information Systems.

Having in mind the pyramid of decision making levels within the organization (Figure 4), an integrated solution is obvious to be required to provide added value and reusability to the organization. In our approach, in order to support the decision process at the highest level, the application of BSC is suggested, for defining the strategic objectives and the necessary initiatives that the organization has to take. For the middle level decision support, ANP is used in order to assist the process of selecting the most beneficial QMS.

To give an insight on the quality management process within the organization, it is handled manually or with the use of ad-hoc applications developed locally at each different country of the multi-national company. The quality management process includes quality controls, report creation towards the top management and compliance control against to quality standards.

The different threads of the quality process are presented in Figure 5. The complexity of this process is substantial since it involves a large number of stakeholders, a large number of quality controls and control points. Some process statistics taken for a 4 years' period are presented in Table 1. The need is evident to merge multiple and interlinked activities under a common IT platform of management and processing.

\subsection{Developing the Scorecard}

The first step of our approach was the development of the strategy map for the organization under study. As we already mentioned, the strategy map defines the

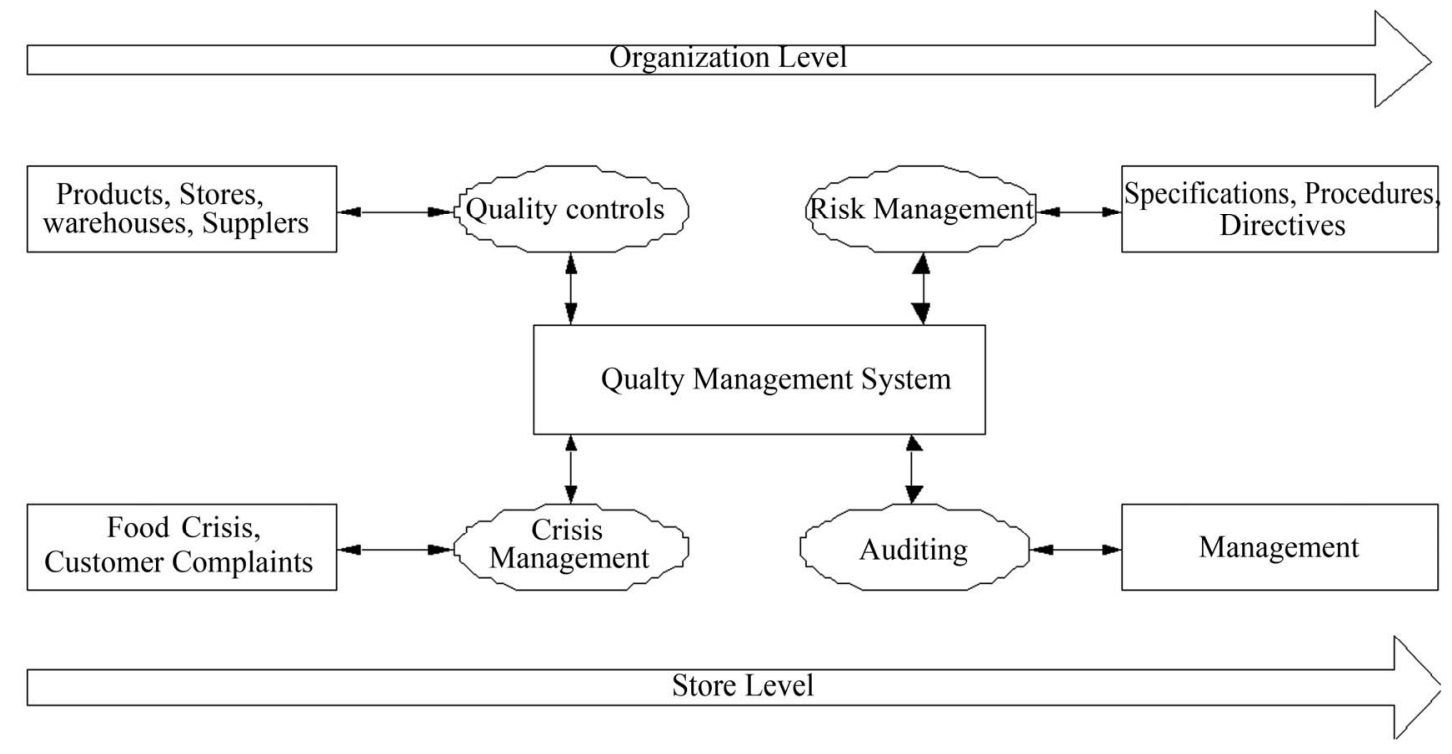

Figure 5. Quality management system. 
Table 1. Quality control in the organization.

\begin{tabular}{clc}
\hline No & \multicolumn{1}{c}{ Activity } & $\begin{array}{c}\text { Volume for a } \\
\text { Period of 4 } \\
\text { Years }\end{array}$ \\
\hline 1 & Quality Control of Products (Lab Tests) & 9700 \\
2 & Quality Control at the Level of Stores & 850 \\
3 & Supplier Control (Providers) & 150 \\
4 & Supplier Control (Agriculture Products) & 60 \\
5 & Production of Reports & 1300 \\
6 & Customer Complaints & 4500 \\
7 & Crisis Management & 200 \\
\hline
\end{tabular}

strategic objectives of the organization for every perspective of the balanced scorecard and interlinks these objectives with cause-effect relations. The cause-effect relations define a finish-to-start relationship between objectives. Figure 6 presents the strategic map for the organization. The arrow connections imply causeeffect relation, e.g. Process Quality Assurance and Process Standardization are prerequisites for Product Quality Improvement or that Service Quality Assurance is a prerequisite for Customer Satisfaction.

The second step of our method is the detailed definition of each strategic objective. For each strategic objective we need to define the metrics that will be used to measure the performance related with the objective, its scope, the measurement frequency (yearly, monthly), etc.

Additionally, in order to be able to compare and quantitatively evaluate each objective, we need to assign a weight to each goal within the perspective. A snapshot of the detailed definition of some of the strategic objectives is presented in Table 2. As it appears in the table, the implementation of a QMS is the proposed strategic initiative for some objectives (CP2, CP3).

In order to calculate the priorities of the organization's strategy regarding the initiatives to take, we add the products of the weights of every strategic objective with the weight of the hosting perspective [21]. E.g. Process standardization, Process Quality Assurance and Service Quality Assurance suggest QMS as the preferred initiative to be undertaken. After doing these calculations, we end up to a score of $39 \%$ for QMS as the suggested strategic initiative. For all calculations, as presented in Figure 7, we have used the tool Balanced Scorecard Designer (http://www.strategy2act.com). Balanced Scorecard Designer is a tool that helps in building balance scorecards.

Having decided that the correct strategic initiative to be undertaken is the development of QMS, the next step is to proceed with the evaluation of alternative

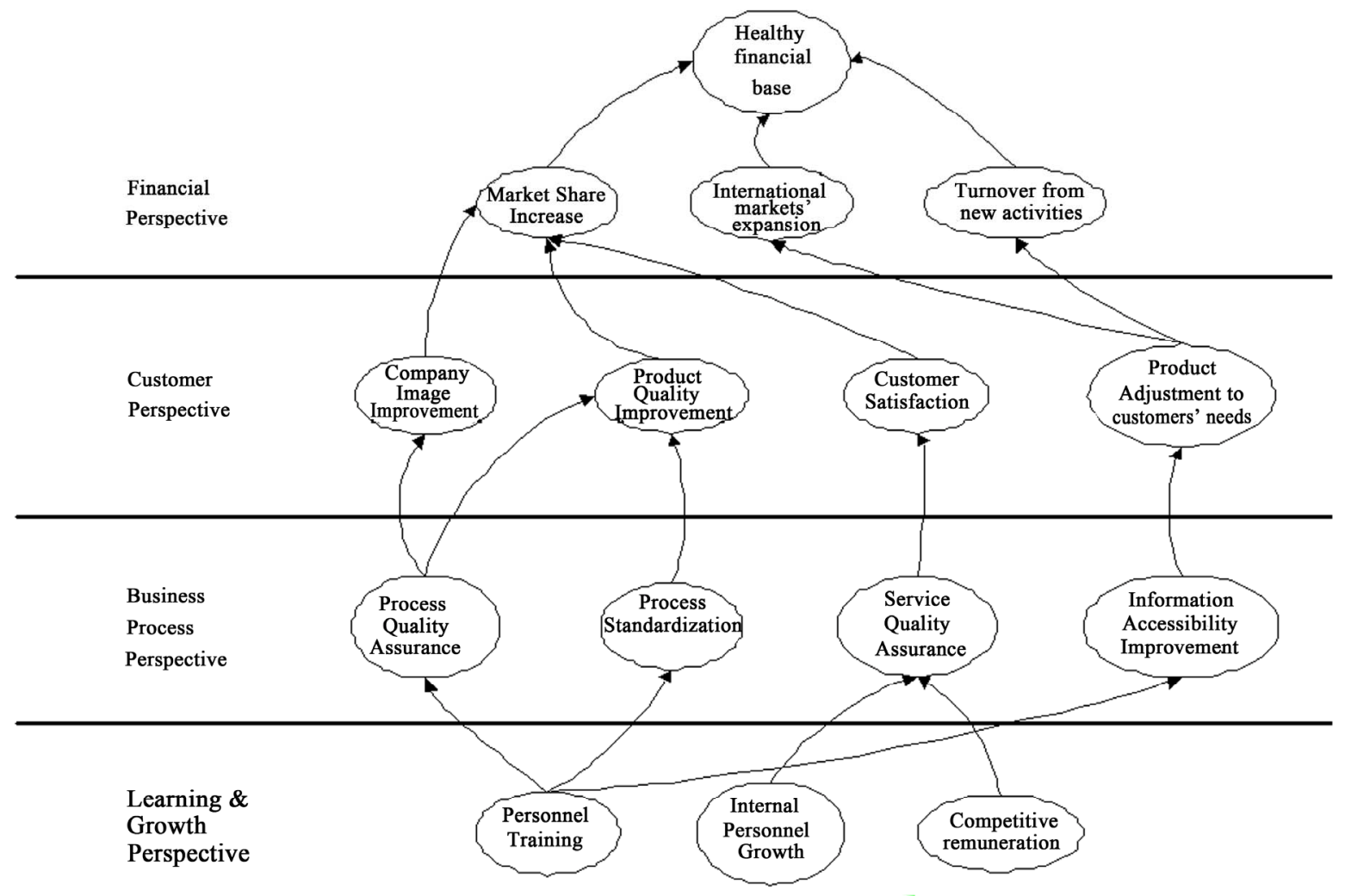

Figure 6. Strategic map of the organization. 
Table 2. Snapshot of the analysis of Strategic goals and performance measures.

\begin{tabular}{|c|c|c|c|c|c|c|}
\hline $\begin{array}{l}\text { Strategic } \\
\text { objectives }\end{array}$ & Objective description & $\begin{array}{l}\text { Performance } \\
\text { measures }\end{array}$ & Target & Frequency & Weight & $\begin{array}{l}\text { Strategic Ini- } \\
\text { tiatives }\end{array}$ \\
\hline $\begin{array}{l}\text { Product quality } \\
\text { improvement } \\
\text { (CP2) }\end{array}$ & $\begin{array}{l}\text { The target is to improve product } \\
\text { quality and its maintenance to } \\
\text { high level, allowing the organi- } \\
\text { zation to be considered as "best } \\
\text { in class" }\end{array}$ & $\begin{array}{l}\text { Minimization of the ratio of } \\
\text { defective items versus total } \\
\text { items produced (per prod- } \\
\text { uct) }\end{array}$ & $0.01 \%$ & Yearly & 4 & $\begin{array}{l}\text { OMS Imple- } \\
\text { mentation }\end{array}$ \\
\hline $\begin{array}{l}\text { Customer } \\
\text { Satisfaction (CP3) }\end{array}$ & $\begin{array}{l}\text { The target is to maintain cus- } \\
\text { tomer satisfaction in the highest } \\
\text { level }\end{array}$ & $\begin{array}{l}\text { Minimization of the com- } \\
\text { plaints per store ratio }\end{array}$ & $5 \%$ & Yearly & 3 & $\begin{array}{l}\text { OMS Imple- } \\
\text { mentation }\end{array}$ \\
\hline $\begin{array}{l}\text { Product adjust- } \\
\text { ment to custom- } \\
\text { ers' needs (CP4) }\end{array}$ & $\begin{array}{l}\text { The target is to adjust products } \\
\text { customer' needs ,using data like } \\
\text { cultural habits, geographical } \\
\text { position or customer' habits for } \\
\text { sales maximization }\end{array}$ & $\begin{array}{l}\text { Ratio of special products' } \\
\text { gross profit per their sales }\end{array}$ & $10 \%$ & Yearly & 1 & $\begin{array}{l}\text { OMS Imple- } \\
\text { mentation }\end{array}$ \\
\hline
\end{tabular}

QM systems.

As a last comment, what must be clear for BSC is that it requires the participation of all the organization, lead by a project team or in other cases the management team, for all the steps mentioned above.

\subsection{Applying Financial Measures}

The organization sent Request for Information (RFI) to different vendors in a form of questionnaire and received information from 10 vendors referring to 10 different QMS systems. The project team evaluated them and eliminated those with the lower performance, resulting in to three alternatives, the systems A, B, C (this process is not presented in the case study). Selecting the alternatives from the successful ones in their field of activity by using the preliminary elimination increases the quality of the decision [22].

An initial analysis of the investments was done for a period of six years calculating the Total Cost of Ownership (TCO). TCO is a financial estimate that determines direct and indirect costs related with an IT system. It is quite useful, since it takes into account the operating cost of a system which in the case of IT system is comparable with the initial investment and significant.

Table 3 presents the TCO for the QMS for a period of six years for the three preferred alternatives [21]. A short description of the process to end up to the three preferred alternatives is described in paragraph 3.3.

In order to apply the financial methods we need to calculate the benefits of installing a QMS system to the organization by qualifying and valuating the activities of Table 1. The key metric that was used for producing the financial benefits is the average man-hours spent on each activity at the company level, number that came as a feedback from the HR department of the organization [21] (see Table 4).

Additionally, we calculate an increase of $10 \%$ for each year, attributed to the organization's organic growth.
The calculations of the NPV, IRR and ROI for the three alternatives are presented in Table 5.

Consequently, one can progress the alternative B as the most preferable solution, as it proves to have the biggest ROI, as well as $N P V$ and ROI. Still, this result depends only on financial measures and is not taking into consideration intangible criteria, such as functionality, that are examined within the ANP framework.

\subsection{Applying Analytical Network Process}

The next step in our approach was the application of an analytical method for evaluation and selection. In our case, we have decided to follow ANP due to its superiority in defining relationships between the criteria.

To setup the basis for the evaluation of the three different products/vendors a set of criteria was created by consulting users during a workshop (see Table 6). Afterwards, the criteria were sorted in four major categories: Cost, Functionality, Technology and Supplier. For each one of them, there were sub criteria (that can be found below). In the 1st step of the ANP algorithm, the problem and scope definition takes place, as follows:

All the criteria and their connections of the ANP model can be seen in Figure 8:

Among others, it is worth to observe 3 points:

1) The element DB connectivity and the relative clusters/elements it is connected (can be seen in bold squares for clusters Alternatives and Supplier)

2) Feedback takes place between clusters Alternatives and Cost

3) Inner-dependence appears in cluster Functionality, meaning that there is an element in this cluster that is connected with an element within Functionality.

Like AHP, pair wise comparisons take place between elements based on the Saaty's Fundamental Scale of Absolute Numbers [23] (see Table 7).

Each element in compared to all other elements, using the scale presented, for defining their relative importance. 
Table 3. TCO for QMS.

\begin{tabular}{cccc}
\hline & $\begin{array}{c}\text { Alternative } \\
\text { A }\end{array}$ & $\begin{array}{c}\text { Alternative } \\
\text { B }\end{array}$ & $\begin{array}{c}\text { Alternative } \\
\text { C }\end{array}$ \\
\hline $\begin{array}{c}\text { Investment } \\
\text { Cost } \\
\text { Operating } \\
\text { Costs }\end{array}$ & 248,500 & 134,000 & 188,000 \\
\hline
\end{tabular}

Table 4. Financial benefit realized per activity.

\begin{tabular}{lc}
\hline Activities & Financial Benefit \\
\hline Quality control of products (lab tests) & 43,650 \\
Quality control at the level of stores & 61,200 \\
Supplier control (providers) & 5400 \\
Supplier control (agriculture products) & 2160 \\
Production of Reports & 5850 \\
Customer complaints & 20,250 \\
Crisis management & 3600 \\
\end{tabular}

Table 5. Application of NPV, IRR and ROI for QMS.

\begin{tabular}{cccc}
\hline & Alternative A & Alternative B & Alternative C \\
\hline $\boldsymbol{N P V}$ & 316753.90 & 495237.08 & 409694.67 \\
$\mathbf{I R R}$ & $45.08 \%$ & $102.25 \%$ & $67.42 \%$ \\
$\mathbf{R O I}$ & $119.30 \%$ & $331.64 \%$ & $194.60 \%$ \\
\hline
\end{tabular}

Table 6. QMS Selection criteria.

\begin{tabular}{cl}
\hline C1: Cost & C11: Implementation cost \\
C12: License cost \\
C13: Maintenance cost \\
\\
C21: Email notification \\
C22: Flexibility \\
C23: Product audit \\
C24: Reports \\
C25: Store audit \\
C26: Supplier audit \\
C27: Security \\
\\
C31: Company profile \\
C32: Implementation time \\
C33: International solution \\
\\
C3: Supplier & C41: Databases \\
& C42: DB connectivity \\
C43: Infrastructure \\
C44: Migration tools \\
C45: Reporting tools \\
C46: Web application \\
\hline
\end{tabular}

Table 7. Saaty's Fundamental Scale of Absolute Numbers.

\begin{tabular}{cc}
\hline Numerical Rating & Verbal Judgments of Preferences \\
\hline 9 & Extremely preferred \\
8 & Very strongly to extremely \\
7 & Very strongly preferred \\
6 & Strongly to very strongly \\
5 & Strongly preferred \\
4 & Moderately to strongly \\
3 & Moderately preferred \\
2 & Equally to moderately \\
1 & Equally preferred \\
\hline
\end{tabular}

For example, the pair wise comparison between License cost, Implementation cost and Maintenance cost shows that License cost is moderately more important (3 times) than Implementation cost and Maintenance cost. Implementation and Maintenance cost have the same importance.

After constructing the pair wise comparison matrix, we can now calculate the priority of each element in terms of its contribution to the overall goal of selecting the best system. This step of the process is called synthesis and the results are presented in Table 8.

Following the same process, all priority (or Eigen) vectors are produced and are finally put in the appropriate positions in the supermatrix. In our case study we have used Super Decisions tool (http://www.super-decisions.com) to operate and demonstrate the whole process (Table 9).

Checking on the sub-matrix having as column and row "Functionality", it appears the aforementioned inner dependence of element C24: Reports with regards to all the other elements of the cluster it belongs. When values are zero this implies that the specific elements do not depend to the examined element. Feedback relationship appears in the sub matrix having as column the cluster Alternatives and as row the cluster Technology, where the elements of Technology were compared with regards to the Alternatives (in bold the values for System B). Finally, total zero values in the sub-matrix having as column the cluster Technology and as row the cluster Cost indicate that there is no connection between of Cost with regards to Technology, as it can be also seen in the model (no arrow from Technology to Cost).

The last step of synthesis, pair wise comparisons take place between clusters for the creation of the Cluster Weights Matrix [24]. The reason of creating Cluster Weights Matrix is that in every cluster there is an element with the highest priority. That does not necessarily mean that this element has the highest priority among all other elements of the other clusters [9]. There comes the need to compare all the clusters in pairs with regards 


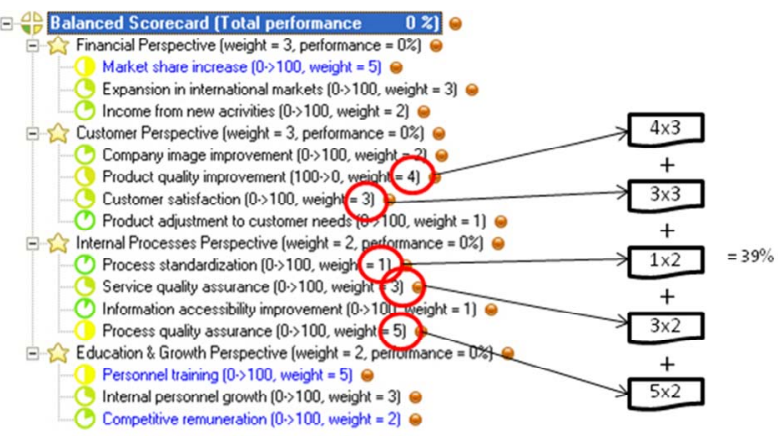

Figure 7. BSC model of the organization.

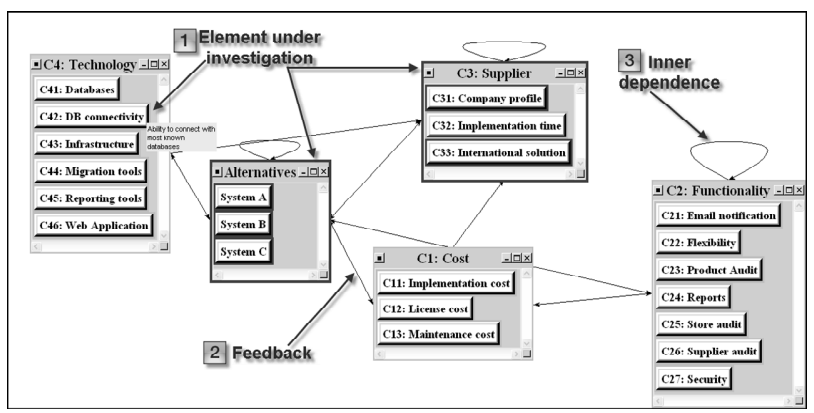

Figure 8. ANP model for QMS selection.

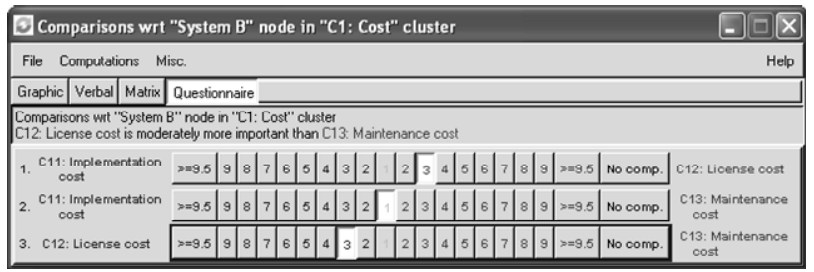

Figure 9. Pair wise comparison of cluster Cost with regards to System B.

Table 8. Pair wise comparison matrix.

\begin{tabular}{lllll}
\hline & C11 & C12 & C13 & Priority vector \\
\hline C11 & 1.000 & 0.333 & 1.000 & \\
C12 & 3.000 & 1.000 & 3.000 & \\
C13 & 1.000 & 0.333 & 1.000 & \\
\hline
\end{tabular}

to a higher control criterion. These comparisons produce a priority vector for every cluster with regards to the others and are used to weigh (multiply) the relative sub matrices of the unweighted supermatrix. E.g. the first value of this vector (first column, first row) is multiplied with all the elements of the relative sub matrix of the unweighted supermatrix, the second value (first column, second row) with the sub matrix having as column the cluster Alternatives and as row the Cost, etc.

The result of this process is the production of the weighted or stochastic supermatrix (Table 11). The transformation to a stochastic per column or simpler stochastic comes out of the fact that the final priorities of the elements have to meet some reduction and cyclicity needs [9]. As every column's summation equals to one, the intuitive reason is to present the priority of every element throughout the network.

The weighted supermatrix is multiplied by itself until the supermatrix's row values converge to the same value for each column of the matrix. The result is the limiting supermatrix (Table 12). Its columns (normalized per cluster) constitute the final priorities of the network, including alternatives.

Focusing to the alternatives sub-matrix, the alternative that has the highest priority shall be chosen and for our case study, System A shall be the proposed solution scoring $\mathbf{4 1 . 7 \%}$. An interesting feature is the (lowest of all) score of System B, that was progressed by the financial methodologies. This can be explained by taking the sum of the 1 column of the Cost sub-matrix $(0.043+$ $0.031+0.021=0.096)$. As it only results in less than $10 \%$ of the total network dependency, it gives a good reason why Cost (and in general tangible criteria) does not hold the major role in IS selection.

\section{Conclusions}

The purpose of this paper was to present a BSC-ANP unified model for IS selection. Through its case study, this model was executed for the selection of a QMS for a multinational retail organization. It is the first time that such a model is presented to assist an organization's strategy in total. Previous attempts were using ANP to "evaluate" the importance of one BSC perspective over the others for insurance or manufacturing organizations $[25,26]$, which is far from the main goal of this model.

Its basic principles support the execution of the organization's strategy by approaching it in high level when applying BSC and to a lower level when executing ANP in order to assist the selection problem that comes out as the proposed initiative from BSC. This is where the strong connection between the two methodologies lies, as the operational performance of the system selected by ANP will then have to be measured in terms of BSC.

The added value of using ANP and not financial methods like NPV, IRR is easily proven by seeing the results of those methodologies where system B (cost effective) appears to be the most preferable alternative (Table 5). The fact that the Cost cluster reached the third place $(0.204$, see Table 10) compared to Alternatives, behind Functionality (0.427) and Technology (0.204), gives a very good reason why the financial methods fail to quantify intangible criteria. The incorporation of the process owners to the evaluation phase is another reason why ANP is a good choice. In that way, resistance to change is significantly 
Table 9. Un-Weighted Supermatrix.

\begin{tabular}{|c|c|c|c|c|c|c|c|c|c|c|c|c|c|c|c|c|c|c|c|c|c|c|c|}
\hline & \multicolumn{3}{|c|}{ Alternatives } & \multicolumn{3}{|c|}{ C1: Cost } & \multicolumn{7}{|c|}{ C2: Functionality } & \multicolumn{3}{|c|}{ C3: Supplier } & \multicolumn{6}{|c|}{ C4: Technology } \\
\hline & & A & $B$ & c & 11 & C12 & 13 & 21 & $\mathrm{C} 22$ & C32 & C24 & $\mathrm{C} 25$ & 26 & 227 & 31 & $\mathrm{C} 32$ & C33 & 41 & 42 & $\mathrm{C} 43$ & C44 & $\mathrm{C} 45$ & 46 \\
\hline 离 & & 0,167 & 0,000 & 0,750 & 571 & 0,571 & 0.443 & .210 & 0,184 & 184 & 0.260 & 1.200 & 0.260 & 184 & 0,169 & 0,550 & 0.200 & 400 & 1,333 & 143 & 1,333 & 169 & .128 \\
\hline \multirow{3}{*}{ 范 } & C11 & 0,637 & 0,200 & 0,429 & \multirow{3}{*}{\multicolumn{4}{|c|}{$\begin{array}{l}\text { Eigenvector of pairwise } \\
\text { comparison of cluster Cost } \\
\text { with regards to System B }\end{array}$}} & 000 & 0,000 & 0.455 & 0,000 & 0,000 & 0,000 & 0,000 & 0,000 & 0,000 & 0,000 & 0,000 & 0,000 & 0,000 & 0,000 & 0,000 \\
\hline & C12 & 0,105 & 0,600 & \multirow{2}{*}{$\int_{0,143}$} & & & & & t 000 & 0,000 & 0,091 & 0,000 & 0,000 & 0,000 & 0,000 & 0,000 & 0,000 & 0,000 & 0,000 & 0,000 & 0,000 & 0,000 & 0,000 \\
\hline & $\mathrm{C} 13$ & 0,258 & 0,200 & & & & & & 000 & 0,000 & 0.455 & 0,000 & 0,000 & 0,000 & 0,000 & 0,000 & 0,000 & 0,000 & 0,000 & 0,000 & 0,000 & 0,000 & 0,000 \\
\hline \multirow{5}{*}{ 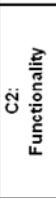 } & C21 & 0,042 & 0.049 & 0,038 & 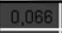 & 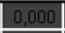 & 0.056 & 0,000 & 0,000 & 0,000 & 0,000 & 0,000 & 0,000 & 0,000 & 0,000 & 0,000 & 0,000 & 0,000 & 0,000 & 0,000 & 0,000 & 0,000 & 0,000 \\
\hline & $\mathrm{C} 24$ & 0,115 & 0,049 & 0,059 & & 0,0 & 0,066 & 0,000 & 0,000 & 000 & 0,000 & 0,000 & 0,000 & 0,000 & & 0, & 0, & 00 & 0,000 & & 0 & 0 & 0,000 \\
\hline & $\mathrm{C} 25$ & 0,131 & 0,119 & 0,102 & 13 & 0.0 & 0,140 & 0,000 & 0,000 & 0,000 & 0,200 & 0,000 & 0,000 & 0,000 & & 0 & 0, & 10 & 0,000 & 00 & 0 & 0 & 00 \\
\hline & $\mathrm{C} 26$ & 0,131 & 0.119 & 0,102 & 1 & 0,00 & 0,149 & 0,000 & 0,000 & 10 & 0 & 0,00 & 0,000 & 0,000 & 000 & 0 & 0,000 & 0 & 0 & 000 & 0 & 0 & 000 \\
\hline & $\mathrm{C} 27$ & .089 & 0,294 & 0,357 & & 1.00 & 0,063 & 0,833 & 0,000 & 0,000 & $00 \%$ s. & 0,000 & \multirow[t]{2}{*}{0,000} & 0,000 & 0,000 & 0 & 0,0 & 00 & 1,000 & 0,000 & 0 & 0 & 0,000 \\
\hline \multirow{2}{*}{ 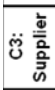 } & C31 & 0,276 & 122 & 0,210 & 286 & 0,000 & 0,250 & 000 & 0,000 & 0 & 0,000 & 0,0 & & 0,0 & 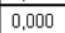 & 0 & 0,250 & 0,000 & 0,250 & 0,000 & 0 & 0 , & 0,000 \\
\hline & $\mathrm{C} 32$ & 0,128 & 0,648 & 0,550 & 0,143 & 0,000 & 0,000 & 0,000 & 0,000 & 0 & 0,000 & \multicolumn{4}{|c|}{$\begin{array}{c}\text { Inner dependence } \\
\text { with regards to } \\
\text { element C24: Reports }\end{array}$} & 0,000 & 0,750 & 0,000 & 0,000 & U & 00 & 0,200 & 0,000 \\
\hline 0 岳 & & 0,09 ? & 0,07 & & & & & & 0,00 & 0,0 & 0,00 & 0,000 & 0,00 & 0,000 & 0,0 & 0,0 & 0,00 & 0,000 & 0,000 & 000 & 00 & 0,000 & 0,000 \\
\hline$\stackrel{\varpi}{\vdash}$ & & 0,332 & 0,383 & vo & & & & & 0,000 & 0,000 & 0,00 & 0,000 & $0,($ & 0,000 & 0,0 & 0,000 & 0, & 0,000 & 000 & IU & 00 & 0,000 & 0,000 \\
\hline & & 089 & & 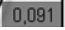 & 000 & 0,000 & & 0,000 & 0,000 & 0,000 & 0,000 & 0,000 & 0,000 & 0,0 & 0,000 & 0,000 & 0,000 & 0,000 & 0,000 & 0,000 & 0,000 & 0,000 & 0,000 \\
\hline
\end{tabular}

Table 10. Cluster Weights Matrix.

\begin{tabular}{cccccc}
\hline & Alternatives & C1:Cost & C2:Functionality & C3:Supplier & C4:Tcchnology \\
\hline Alternatives & 0.074 & 0.156 & 0.109 & 0.667 & 0.250 \\
C1:Cost & 0.204 & 0.000 & 0.309 & 0.000 & 0.000 \\
C2:Functionality & 0.427 & 0.659 & 0.582 & 0.000 & 0.000 \\
C3:Supplier & 0.091 & 0.185 & 0.000 & 0.000 & 0.750 \\
C4:Tcchnology & 0.204 & 0.000 & 0.000 & 1.000 & 1.000 \\
Row sum & 1.000 & 1.000 & 1.000 & \\
\hline
\end{tabular}

Table 11. Weighted Supermatrix.

\begin{tabular}{|c|c|c|c|c|c|c|c|c|c|c|c|c|c|c|c|c|c|c|c|c|c|c|c|}
\hline & & \multicolumn{3}{|c|}{ Alternatives } & \multicolumn{3}{|c|}{ C1: Cost } & \multicolumn{7}{|c|}{ C2: Functionality } & \multicolumn{3}{|c|}{ C3: Supplier } & \multicolumn{6}{|c|}{ C4: Technology } \\
\hline & & A & $B$ & c & C11 & $\mathrm{C} 12$ & $\mathrm{C} 13$ & $\mathrm{C} 21$ & $\mathrm{C} 22$ & $\mathrm{C} 32$ & $\mathrm{C} 24$ & $\mathrm{C} 25$ & $\mathrm{C} 26$ & $\mathrm{C} 27$ & $\mathrm{C} 31$ & $\mathrm{C} 32$ & $\mathrm{C} 33$ & $\mathrm{C} 41$ & $\mathrm{C} 42$ & $\mathrm{C} 43$ & $\mathrm{C} 44$ & $\mathrm{C} 45$ & $\mathrm{C} 46$ \\
\hline \multirow{3}{*}{ 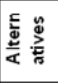 } & & 0,000 & 0,012 & 0,019 & 0,022 & 0,143 & 0,026 & 0,087 & 0,584 & 0,584 & 0,045 & 0,400 & 0,413 & 0,584 & 0,296 & 0,240 & 0,267 & 0,400 & 0,083 & 0,571 & 0,083 & 0,111 & 0,595 \\
\hline & & 0,012 & 0,000 & 0.056 & 0,089 & 0,571 & 0,069 & 0,033 & 0.184 & 0.184 & 0,028 & 0.200 & 0,260 & 0.184 & 0.113 & 0.550 & 0.133 & 0.400 & 0.083 & 0.143 & 0,083 & 0.042 & 0.128 \\
\hline & $\mathrm{C}$ & \begin{tabular}{|l}
0,062 \\
\end{tabular} & 0,062 & 0,000 & 0,045 & 0,286 & 0,061 & 0,038 & 0,232 & 0,232 & 0,036 & 0,400 & 0,327 & 0,232 & 0,258 & 0,210 & 0,267 & 0,200 & 0,083 & 0,286 & 0,083 & 0,097 & 0,276 \\
\hline \multirow{3}{*}{ 苑 范 } & C11 & 0,130 & 0,041 & 0,088 & 0,000 & 0,000 & 0,000 & 0,000 & 0,000 & 0,000 & 0,140 & 0,000 & 0,000 & 0,000 & 0,000 & 0,000 & 0,000 & 0,000 & 0,000 & 0,000 & 0,000 & 0,000 & 0,000 \\
\hline & C12 & 0,021 & 0,123 & 0,088 & 0,000 & 0,000 & 0,000 & 0,000 & 0,000 & 0,000 & 0,028 & 0,000 & 0,000 & 0,000 & 0,000 & 0,000 & 0,000 & 0,000 & 0,000 & 0,000 & 0,000 & 0,000 & 0,000 \\
\hline & $\mathrm{C}_{13}$ & 0,053 & 0,041 & 0,029 & 0,000 & 0,000 & 0,000 & 0,000 & 0,000 & 0,000 & 0,140 & 0,000 & 0,000 & 0,000 & 0,000 & 0,000 & 0,000 & 0,000 & 0,000 & 0,000 & 0,000 & 0,000 & 0,000 \\
\hline \multirow{7}{*}{ 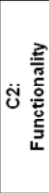 } & $\mathrm{C} 21$ & 0,018 & 0,021 & 0,016 & 0,044 & .000 & 0,037 & 0,000 & 0,000 & 0,000 & 0,000 & 0,000 & 0,000 & 0,000 & 0,000 & 0,000 & 0,000 & 0,000 & 0,000 & 0,000 & 0,000 & 0,000 & 0,000 \\
\hline & C22 & 0.078 & 0,048 & 0,063 & 0.14 & 0.00 & 0.098 & 0,140 & 0,000 & 0,000 & 0.000 & 0,000 & 0,000 & 0,000 & 0.000 & 0.000 & 0.000 & 0.000 & 0,000 & 0.000 & 0,000 & 0.000 & 0.000 \\
\hline & $\mathrm{C} 23$ & 0,132 & 0,110 & 0,083 & 0,213 & 0,00 & 0,248 & 0,000 & 0,000 & 0,000 & 0,349 & 0,000 & 0,000 & 0,000 & 0,000 & 0,000 & 0,000 & 0,000 & 0,000 & 0,000 & 0,000 & 0,000 & 0,000 \\
\hline & $\mathrm{C} 24$ & 0,049 & 0,021 & 0,025 & 0,044 & 0,000 & 0,044 & 0,000 & 0,000 & 0,000 & 0,000 & 0,000 & 0,000 & 0,000 & 0,000 & 0,000 & 0,000 & 0,000 & 0,000 & 0,000 & 0,000 & 0,000 & 0,000 \\
\hline & $\mathrm{C} 25$ & 0,056 & 0,051 & 0,043 & 0,08 & 0,000 & 0,092 & 0,000 & 0,000 & 0,000 & 0,116 & 0,000 & 0,000 & 0,000 & 0,000 & 0,000 & 0,000 & 0,000 & 0,000 & 0,000 & 0,000 & 0,000 & 0,000 \\
\hline & $\mathrm{C} 26$ & 0,056 & 0,051 & 0,043 & 0,087 & 0,000 & 0,098 & 0,000 & 0,000 & 0,000 & 0,116 & 0,000 & 0,000 & 0,000 & 0,000 & 0,000 & 0,000 & 0,000 & 0,000 & 0,000 & 0,000 & 0,000 & 0,000 \\
\hline & $\mathrm{C} 27$ & 0,038 & 0,125 & 0,152 & 0,044 & 0,000 & 0,041 & 0,701 & 0,000 & 0,000 & 0,000 & 0,000 & 0,000 & 0,000 & 0,000 & 0,000 & 0,000 & 0,000 & 0,000 & 0,000 & 0,000 & 0,000 & 0,000 \\
\hline \multirow{3}{*}{ 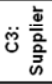 } & $\mathrm{C} 31$ & 0,025 & 0,011 & 0,019 & 0,053 & 0,000 & 0,046 & 0,000 & 0,000 & 0,000 & 0,000 & 0,000 & 0,000 & 0,000 & 0,000 & 0,000 & 0,083 & 0,000 & 0,187 & 0,000 & 0,150 & 0,150 & 0,000 \\
\hline & C32 & 0,012 & 0,059 & 0,050 & 0,026 & 0,000 & 0,000 & 0,000 & 0,000 & 0,000 & 0,000 & 0,000 & 0,000 & 0,000 & 0,067 & 0,000 & 0,250 & 0,000 & 0,000 & 0,000 & 0,150 & 0,150 & 0,000 \\
\hline & C33 & 0,054 & 0,021 & 0,022 & 0,106 & 0,000 & 0,139 & 0,000 & 0,000 & 0,000 & 0,000 & 0,000 & 0,000 & 0,000 & 0,267 & 0,000 & 0,000 & 0,000 & 0,563 & 0,000 & 0,450 & 0,450 & 0,000 \\
\hline \multirow{6}{*}{ 产 } & C41 & 0,041 & 0,039 & 0,046 & 0,000 & 0,000 & 0,000 & 0,000 & 0,000 & 0,000 & 0,000 & 0,000 & 0,000 & 0,000 & 0,000 & 0,000 & 0,000 & 0,000 & 0,000 & 0,000 & 0,000 & 0,000 & 0,000 \\
\hline & $\mathrm{C} 42$ & \begin{tabular}{|l}
0,044 \\
\end{tabular} & 0,039 & 0,046 & 0,000 & 0,000 & 0,000 & 0,000 & 0,000 & 0,000 & 0,000 & 0,000 & 0,000 & 0,000 & 0,000 & 0,000 & 0,000 & 0,000 & 0,000 & 0,000 & 0,000 & 0,000 & 0,000 \\
\hline & $\mathrm{C} 43$ & 0.014 & 0.017 & 0.009 & 0,000 & 0,000 & 0,000 & 0,000 & 0,000 & 0,000 & 0,000 & 0.000 & 0,000 & 0,000 & 0,000 & 0,000 & 0.000 & 0,000 & 0,000 & 0,000 & 0,000 & 0.000 & 0,000 \\
\hline & C44 & 0,019 & 0,015 & 0,009 & 0,000 & 0,000 & 0,000 & 0,000 & 0,000 & 0,000 & 0,000 & 0,000 & 0,000 & 0,000 & 0,000 & 0,000 & 0,000 & 0,000 & 0,000 & 0,000 & 0,000 & 0,000 & 0,000 \\
\hline & C45 & 0,068 & 0,078 & 0,074 & 0,000 & 0,000 & 0,000 & 0,000 & 0,000 & 0,000 & 0,000 & 0,000 & 0,000 & 0,000 & 0,000 & 0,000 & 0,000 & 0,000 & 0,000 & 0,000 & 0,000 & 0,000 & 0,000 \\
\hline & $\mathrm{C} 46$ & 0,018 & 0,016 & 0,019 & 0,000 & 0,000 & 0,000 & 0,000 & 0,000 & 0,000 & 0,000 & 0,000 & 0,000 & 0,000 & 0,000 & 0,000 & 0,000 & 0,000 & 0,000 & 0,000 & 0,000 & 0,000 & 0,000 \\
\hline
\end{tabular}

lower than the one that could be caused if system B was selected. This would happen because selection based on financial methodologies is done by a team of experts and not from the operational teams. Seeing this the opposite way, this incorporation of process owners means increased resources and increased resources mean higher costs. Furthermore, possible changes to the selection criteria could imply additional evaluations (meaning ad- ditional administrative costs). Nevertheless, selection systems like the one used in this study (SuperDecisions) mitigate these risks and lower the calculation/administration costs, not to mention the cost of a system that will be selected based only on cost-effective criteria but will not succeed its goals.

As for AHP, the feature of comparison with regards to Alternatives is not available. The obvious and reasonable 
Table 12. Limiting supermatrix.

\begin{tabular}{|c|c|c|c|c|c|c|c|c|c|c|c|c|c|c|c|c|c|c|c|c|c|c|}
\hline & \multicolumn{3}{|c|}{ Alternatives } & \multicolumn{3}{|c|}{ C1: Cos } & \multicolumn{7}{|c|}{ C2: Functionality } & \multicolumn{3}{|c|}{. } & \multicolumn{6}{|c|}{ CA: T } \\
\hline & & & & C11 & $\mathrm{C}_{12}$ & & & 22 & $\mathrm{C} 32$ & $\mathrm{C} 24$ & C25 & 26 & 2.7 & 31 & $\mathrm{C} 32$ & 33 & & 42 & $\mathrm{C} 43$ & C44 & 045 & 46 \\
\hline \multirow{3}{*}{ 战 } & 184 & 184 & & & & & & .184 & 184 & 184 & & & 194 & 184 & & & & & & & & \\
\hline & 122 & 122 & 122 & I & 0 & & & 0.122 & 0,122 & 122 & 122 & & 122 & 122 & 22 & 122 & & 122 & & & & \\
\hline & .135 & 0.135 & 0,135 & & & & & 0,135 & 1.135 & & & & 135 & 135 & & 0.135 & & .135 & & & & 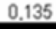 \\
\hline \multirow{3}{*}{ ث̈ㅇํㅇ } & 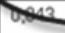 & 0.04 & 2013 & & & & & 0.043 & 0.043 & & & & 0.0 & 43 & & 43 & .043 & 0.043 & 0. & 0.043 & 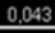 & .043 \\
\hline & 0.031 & & 0,031 & & & & & 0.031 & 0.031 & & & & & & & & & & & & & \\
\hline & 021 & & 021 & 021 & & & & 0.021 & 021 & & & & & & & & & & & & & \\
\hline \multirow{7}{*}{ ปั่ } & 11 & & o & & & & & 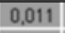 & , טiI & & & & & & & & & & & & & 011 \\
\hline & 38 & 038 & .03 & & & & & & & & Us & & & 80 & & 0,0 & & 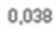 & & & & 034 \\
\hline & 070 & 07 & 07 & & & & & & & & & & & & & & & & & & & \\
\hline & 18 & 01 & 01 & & & & & & & & & & & & & & & & & & & \\
\hline & 030 & 03 & 03 & & & & & & & & & & & & & & & & & & & 30 \\
\hline & 030 & 030 & 030 & & & & & & & & & & & & & & & & & & & \\
\hline & 053 & & 053 & & & & & & & & 0.053 & 0,053 & 0.000 & 3 & & & & & & & & \\
\hline \multirow{3}{*}{ 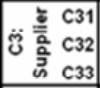 } & 26 & & 026 & 26 & & & \multicolumn{7}{|c|}{ | } & 0,026 & & & & & & & & \\
\hline & 039 & 03 & 0 & 039 & 03 & & \multirow{5}{*}{\multicolumn{7}{|c|}{$\begin{array}{c}0,184+0,122+0,135=0,441 \\
\text { System A: } 0,184: 0,441=\mathbf{4 1 , 7} \% \\
\text { System B: } 0,122: 0,441=\mathbf{2 7 , 7} \% \\
\text { System C: } 0,135: 0,441=\mathbf{3 0 , 6} \%\end{array}$}} & U39 & 0. & 0.0 & 9 & 0.039 & 0.039 & 9 & 9 & .039 \\
\hline & 0.058 & 058 & .058 & 058 & 058 & & & & & & & & & 058 & 0,058 & 0,058 & 0.058 & 0.058 & 0,058 & 0.058 & 0. & 0.058 \\
\hline \multirow{6}{*}{ 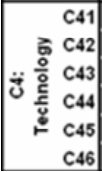 } & 019 & & .019 & & & & & & & & & & & 01 & & 0 & & 0.0 & & & & \\
\hline & 019 & & 0.019 & & 0,019 & & & & & & & & & pis & & 0. & & & & & & . \\
\hline & 006 & & $\underline{-1}$ & 000 & & & & & & & & & & & & & & & & & & .0uc \\
\hline & .007 & & 0.007 & & & & & & & & & & & .007 & & & & I & I & JI & 07 & 000 \\
\hline & 1.032 & & s. & & & & & & & & & & & 0,032 & & & & & & & & 00 \\
\hline & 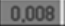 & 0.008 & & & & & & 000 & so & & & & & .008 & & & 0,008 & 0,000 & 0.006 & 0,008 & 0,008 & 0,00 \\
\hline
\end{tabular}

comparison e.g. of the elements of cluster Cost with regards to Alternatives is something that cannot happen in AHP and clearly shows the limitations of this methodology. Still, its wide expansion in all kinds of problems through the years like project delivery method [27], ERP selection [28], etc. makes AHP a reference among MCDM methodologies.

While we believe that the model presented provides value, there are areas for future enhancements and validation. It is acknowledged that the decision levels involved in any selection problem can vary, depending on the organization. Indeed, this is one of the strengths of ANP: the ability to adapt its framework to custom needs. A decision criterion that the organization considers critical can be easily added while the selection problem is ongoing. In that way, due to its general directives, the use of the model can be validated for all kinds of organizations and IS.

Enhancements can also be made in terms of monitoring the performance of the BSC model. As each strategic objective is monitored on a certain frequency, it would be interesting to integrate an iterative process in the model to measure the added value that came out of the implementation of the selected QMS (System A) and its "score" versus the relative strategic objectives (Figure 7). Tools like the one used in this study can easily integrate such processes through business intelligence techniques to give the chance to top management to have a real-time view on the strategy execution.

\section{Acknowledgements}

The authors would like to thank Mr. Robert Elliott from AKS-Labs for his kind offer of a full-feature version of the Balanced Scorecard Designer tool.

\section{References}

[1] Z. Irani and P. Love, "Information Systems Evaluation: Past, Present and Future,” European Journal of Information Systems, Vol. 10, No. 4, 2001, pp. 183-188.

[2] Z. Irani and P. Love, "Evaluating Information Systems. Public and Private Sector," 1st Edition, ButterworthHeinemann, Hungary, 2008.

[3] H. Erdogmus, J. Favaro and W. Strigel, "Return on Investment," IEEE Software, Vol. 21, No. 3, 2004, pp. 18-22. doi:10.1109/MS.2004.1293068

[4] B. Boehm, "Software Engineering Economics," Prentice Hall, Upper Saddle River, 1981.

[5] S. Ross, R. Westerfield and B. Jordan, "Fundamentals of Corporate Finance,” Times Mirror Professional Publishing, New York, 1996.

[6] A. S. Jadhav and R. M. Sonar, "Evaluating and Selecting Software Packages: A Review," Information and Software Technology, Vol. 51, No. 3, 2009, pp. 555-563. doi:10.1016/j.infsof.2008.09.003

[7] O. S. Vaidya and S. Kumar, "Analytic Hierarchy Process: An Overview of Applications,” European Journal of Operational Research, Vol. 169, No. 1, 1996, pp. 1-29. doi:10.1016/j.ejor.2004.04.028

[8] T. L. Saaty, “The Analytic Hierarchy Process: Planning, Priority Setting, Resource Allocation,” McGraw-Hill, Pittsburgh, 1980.

[9] T. L. Saaty, "Decision Making with Dependence and Feedback,” RWS Publications, Pittsburgh, 1996.

[10] T. L. Saaty, "Theory and Applications of the Analytic Network Process: Decision Making with Benefits, Opportunities, Costs, and Risks,” RWS Publications, Pittsburgh, 2005.

[11] K. Hafeez, Y. Zhang and N. Malak, "Determining Key Capabilities of a Firm Using Analytic Hierarchy Process," International Journal of Production Economics, Vol. 
76 , No. 1 , 2002, pp. 39-51. doi:10.1016/S0925-5273(01)00141-4

[12] R. A. Brealey and S. C. Myers, "Capital Investment and Valuation,” McGraw/Hill, New York, 2002.

[13] M. Schniederjans, J. Hamaker and A. Schniederjans, "Information Technology Investment: Decision Making Technology," World Scientific Publishing Company, Singapore, 2004.

[14] L. T. Blank and A. J. Tarquin, "Engineering Economy," 3rd Edition, McGraw-Hill, NewYork, 1989.

[15] J. Karlsson and K. Ryan, "A Cost-Value Approach for Prioritizing Requirements,” IEEE Software, Vol. 14, No. 5, 1997, pp. 67-74. doi:10.1109/52.605933

[16] J. Kontio, "A Case Study in Applying a Systematic Method for COTS Selection," Proceedings of the 18th International Conference on Software Engineering, IEEE Press, New York, 1996. doi:10.1109/ICSE.1996.493416

[17] A. Lozano-Tello and A. Gomez Perez, "BAREMO: How to Choose the Appropriate Software Component Using the Analytic Hierarchy Process," Proceedings of the International Conference on Software Engineering and Knowledge Engineering (SEKE), Skokie, 21-23 June, 2002.

[18] V. Gerogiannis, P. Fitsilis, G. Kakarotzas and A. Tzikas, "Involving Stakeholders in the Selection of a Project and Portfolio Management Tool," 21st Greek Operation Research Conference, Athens, 28-29 May 2009.

[19] R. S. Kaplan and D. P. Norton, “The Balanced Scorecard: Translating Strategy into Action,” Harvard Business Press, Massachusetts, 1996.

[20] H. Ahn, "Applying the Balanced Scorecard Concept: An Experience Report,” Long Range Planning, Vol. 34, No.
4, 2001, pp. 441-461. doi:10.1016/S0024-6301(01)00057-7

[21] K. Viglas, "Evaluation/Selection Methodologies of Information Systems,” Hellenic Open University, Patras, 2009.

[22] C. Gencer and D. Gürpinar, “Analytic Network Process in Supplier Selection: A Case Study in an Electronic Firm,” Applied Mathematical Modelling, Vol. 31, No. 11, 2007, pp. 2475-2486. doi:10.1016/j.apm.2006.10.002

[23] T. L. Saaty, "Fundamentals of the Analytic Network Process,” ISAHP, Kobe, 1999.

[24] S. Percin, "Using the ANP Approach in Selecting and Benchmarking ERP Systems,” Benchmarking: An International Journal, Vol. 15, No. 5, 2008, pp. 630-649.

[25] R. Ak and B. Oztaysi, "Performance Measurement of Insurance Companies by Using Balanced Scorecard and ANP,” Istanbul Technical University, Istanbul, 2009.

[26] I. Yuksel and M. Dagdeviren, "Using the Fuzzy Analytic Network Process (ANP) for Balanced Scorecard (BSC): A Case Study for a Manufacturing Firm,” Expert Systems with Applications, Vol. 37, No. 2, 2010, pp. 1270-1278. doi:10.1016/j.eswa.2009.06.002

[27] M. I. Al Khalil, "Selecting the Appropriate Project Delivery Method Using AHP," International Journal of Project Management, Vol. 20, No. 6, 2002, pp. 469-474. doi:10.1016/S0263-7863(01)00032-1

[28] C. C. Wei, C. F. Chien and M. J. J. Wang, "An AHP-Based Approach to ERP System Selection,” International Journal of Production Economics, Vol. 96, No. 1, 2005, pp. 47-62. doi:10.1016/j.ijpe.2004.03.004 